\title{
Simulações da Previdência Social Brasileira: Estudo de Caso do Regime Jurídico Único - RJU
}

\author{
Paula Bicudo de Castro Magalhães \\ Mirta Noemi Sataka Bugarin
}

\author{
Analista de Finanças e Controle - Secretaria do \\ Tesouro Nacional, Ministério da Fazenda \\ Professora do Departamento de Economia da \\ Universidade de Brasília
}

\section{RESUMO}

O artigo apresenta uma análise das possíveis trajetórias do fluxo do saldo de caixa do Regime Jurídico Único dos servidores do Poder Executivo, sob as reformas institucionais/legais efetuadas e propostas, mediante a utilização de métodos atuariais. Depreende-se dos resultados das diversas simulações realizadas que, ainda na melhor das hipóteses, considerando uma taxa de crescimento de 3\% do PIB real da economia, o déficit do caixa do RJU aumentaria de forma crescente até o ano 2016, a partir do qual diminuiria, atingindo em 2090 a anulação desse déficit, quando a massa de servidores nesse sistema também seria extinta, conforme as normas instituídas pela Lei Geral de Previdência Pública $N^{\circ} 9.7$ I 7, e previstas no Projeto de Lei Complementar 57/99.

\section{PALAVRAS-CHAVE}

Regime Jurídico Único, déficit previdenciário, projeções do déficit

ABSTRACT

The article aims to analyze several alternative paths the deficit's flow in the Brazilian public sector pension system (Regime Jurídico Único-RJU) can take under the implemented as well as proposed reforms by the Congress. To this end, actuarial methods are employed under different alternative hypothesis. The simulation show that, even under the best considered sce-

nario, in which the country's GDP growths at an annual rate of 3\%, the RJU's deficit will continue to increase up to 2016. In other words, only from this date on, the deficit begins to shrink, which could be cancelled off in 2090 when the regime will be closed, according to the recently proposed legal framework.

KEY WORDS

public sector pension system, social security deficit, deficit projections

JEL Classification

H55, C60 


\section{INTRODUÇÃO}

Os sistemas de previdência de vários países vêm passando por um grande processo de reforma. Os principais fatores que levaram às discussões dessas reformas são comuns a todos os países, destacando-se, entre eles, os de ordem demográfica, dados pela conjugação do aumento da expectativa de vida e da redução da taxa de fecundidade, que têm levado ao aumento acentuado da população idosa.

O sistema de previdência adotado no Brasil é o de repartição simples, em que as contribuições previdenciárias pagas pela população ativa destinam-se a cobrir os gastos com os benefícios dos inativos, coexistindo, atualmente, dois regimes previdenciários distintos. O primeiro é o Regime Geral de Previdência Social (RGPS), que rege os trabalhadores do setor privado, e o outro é o Regime Jurídico Único (RJU), criado pela Constituição de 1988 para os servidores públicos, havendo, ainda, a possibilidade de existência de outros regimes próprios de previdência no âmbito da União, Estados e Municípios.

Nesse tipo de sistema, a adequação do sistema ao novo padrão demográfico do País torna-se crucial. No início, na ausência de um estoque de aposentados, os superávits do caixa da Previdência são naturais num sistema jovem. ${ }^{1}$ Porém, quando a população começa a envelhecer, e o número de contribuintes deixa de ser superior ao de inativos, não será possível manter a mesma alíquota de contribuição para poder manter o equilíbrio financeiro do sistema.

No Brasil, em particular, além do novo padrão demográfico em vigor ${ }^{2}$ e da dinâmica nas relações de trabalho, ${ }^{3}$ estabeleceu-se um novo marco institucional/legal, afetando, conseqüentemente, de forma direta, a evolução da arrecadação previdenciária e o equilíbrio financeiro do sistema. Em relação à evolução desse aspecto institucional previdenciário, diversos autores têm en-

l Cabe observar que no Brasil esses saldos superavitários também foram alocados para financiar outras despesas, em particular, de saúde.

2 Ver ORNÉLAS (1999) para um estudo detalhado da mudança na expectativa de vida da população brasileira.

3 A este respeito, ORNÉLAS \& VIEIRA (1999) e GALRÃO (2000), entre outros, desenvolvem estudos das características informais do mercado de trabalho no País, e NAME \& BUGARIN (2003) estimam a evolução da economia submersa brasileira no período recente. 
fatizado características particulares do caso brasileiro, que tenderam a comprometer o equilíbrio financeiro do sistema. Dentre elas podemos mencionar, por exemplo, a expansão da cobertura previdenciária, em particular até a década de 70, como apontado por Oliveira et alii (1997), a aposentadoria precoce por tempo de serviço e a marcante característica da Constituição de 1988, que visa assegurar o acesso de diferentes grupos e categorias aos recursos previdenciários, tal como indicadas por Giambiagi e Além (1997 e 1999). Por sua vez, Pinheiro (1999) aponta que o modelo de previdência, em particular do setor público do País, foi organizado segundo a relação prolabore facto, em que o direito de aposentadoria não está condicionado à contribuição, mas à vinculação do funcionário ao Estado. ${ }^{4}$

O desequilíbrio financeiro conseqüente do sistema previdenciário do País incentivou a discussão sobre a sua reforma, objetivando o saneamento das contas públicas, para o qual tornou-se inevitável e essencial.

Em particular, a discussão sobre a reforma do sistema previdenciário do setor público brasileiro ocupou lugar de destaque, especialmente a partir de 1995, quando se constatou que o principal fator explicativo da resistência à melhora dos resultados primários das contas do governo era o déficit crescente desse sistema.

Devido às características particulares do regime de previdência dos servidores públicos, diferente às correspondentes ao RGPS do setor privado, não há como realizar uma análise conjunta de ambos os regimes, e dada a elevada magnitude relativa que o déficit do regime dos servidores públicos, especialmente a partir de meados da década de 90,5 optou-se, neste trabalho, por analisar os resultados obtidos com as reformas já realizadas ou ainda em andamento apenas do RJU.

4 Os servidores públicos tinham direito à aposentadoria como extensão do fato de trabalharem para o serviço público e, por isso, não contribuíam. Somando-se a esse problema, a Constituição de 1988 igualou todos os funcionários do governo. Até a nova Constituição, certos serviços públicos eram regidos pelas regras do setor privado e, portanto, estavam sujeitos ao teto imposto pela previdência do setor privado. A Constituição também determinou que todos os servidores públicos, agora pertencentes ao Regime Jurídico Único (RJU), receberiam suas aposentadorias de acordo com a última remuneração.

5 Segundo dados do MPSA/SPS, o déficit do RJU de R\$ 15,87 bilhões em 1996 aumentou para R\$ 19,5 bilhões em 1999, e o do RGPS de R\$ 0,31 bilhões em 1996 para R \$ 9,7 bilhões em 1999, a preços constantes de dezembro/99. 
A metodologia utilizada no presente estudo baseia-se em modelos atuariais, desenvolvidos com o intuito de projetar e analisar o comportamento do sistema de RJU no longo prazo. ${ }^{6}$ Dessa forma, procura-se analisar diferentes projeçôes do comportamento do sistema dos servidores civis do Poder Executivo $^{7}$ como um todo, sob cenários alternativos em relação à alíquota e à abrangência da contribuição, utilizando o modelo atuarial proposto por Iyer (1999), considerando os diferentes tipos de benefícios (por aposentadoria, por invalidez, por idade e por tempo de contribuição), e supondo, segundo os moldes propostos pela nova legislação, a extinção de novas entradas no RJU (massa fechada).

Além disso, para realizar as simulações, supõe-se um crescimento do PIB real da economia de 3\% e uma taxa de desconto de $10 \%$. Dentre os resultados obtidos, sob os diferentes cenários alternativos considerados, o mais favorável para as contas públicas é obtido, conforme esperado, no caso extremo em que o servidor não é contemplado com nenhum reajuste salarial, e tanto os ativos quanto os inativos contribuem com uma alíquota de $15 \%$. No entanto, ainda nesse caso extremo, mais favorável para as finanças públicas, somente a partir de 2016 começar-se-ia a observar uma tendência decrescente na trajetória do déficit do sistema, e em termos de valor presente, esse fluxo do déficit do sistema de RJU representaria aproximadamente $0,68 \%$ do valor presente do PIB real, que cresce, nas simulaçóes, a uma taxa hipotética de $3 \%$ anual.

Consideramos ainda oportuno ressaltar que, dessa forma, o presente estudo define o foco de análise sobre o RJU dos servidores públicos do executivo federal, em particular, e que a metodologia empregada baseia-se no cálculo atuarial. ${ }^{8}$ Portanto, o mesmo difere, tanto em termos do escopo da análise quanto metodologicamente, de trabalhos que visam analisar o impacto sobre o bem-estar social da previdência social de repartição mediante modelos

6 Observe que o cálculo atuarial constitui a metodologia mais apropriada dada a natureza da análise ora proposta e as características das reformas propostas para o RJU que serão descritas a seguir.

7 Os dados existentes para os Poderes Legislativo e Judiciário e para os Militares são insuficientes para a aplicação da metodologia atuarial ora proposta.

8 Como exemplos de projeçôes atuariais para o regime de Previdência Social, vide Informe de Previdência Social do MPS (2001). 
de equilíbrio geral, como os realizados, por exemplo, para o caso brasileiro, por Barreto (1997), Lannes Jr. (1999) e Ellery Jr. e Bugarin (2003).

O presente trabalho encontra-se organizado de forma a apresentar, na seção 1, a metodologia desenvolvida especificamente para efetuar as simulações do RJU, contemplando as reformas propostas para o RJU; na seção 2, a análise dos resultados obtidos nessas simulações, e finalmente, na última seção, as conclusões gerais.

\section{METODOLOGLA ATUARIAL UTILIZADA PARA AS PROJEÇÕES DO SALDO DO RJU}

As mudanças impostas pelas reformas previdenciária e administrativa ao Regime Jurídico Único motivaram a realização de novas avaliações dos resultados de suas contas. Diferentes modelos buscam analisar o comportamento dos sistemas previdenciários no curto e longo prazo. Nesta seção é apresentado um modelo atuarial que foi desenvolvido com o intuito de projetar o comportamento da previdência dos servidores públicos brasileiros no longo prazo.

Com base nas mudanças propostas para o RJU, procura-se analisar o comportamento do sistema previdenciário dos servidores como um todo. Devido à indisponibilidade de dados, a projeção é feita apenas para os servidores civis do Poder Executivo. Os dados existentes para os Poderes Legislativo e Judiciário, e para os Militares, são insuficientes para a aplicação da metodologia ora proposta. O modelo atuarial utilizado é baseado em Iyer (1999), considerando os seguintes benefícios: aposentadoria por invalidez, aposentadoria por idade ${ }^{9}$ e pensão por morte.

Como a nova legislação está tendendo à extinção de novas entradas no RJU, supõe-se, nas simulações, que não haverá mais novos servidores ingressando nesse regime de previdência. Portanto, analisa-se como seria o comportamento do déficit previdenciário com a extinção das entradas no RJU. O objetivo é mostrar que, mesmo com todas as reformas efetuadas e com as

$\overline{9}$ Considera-se incluído, nesse grupo, as aposentadorias por tempo de contribuição. 
ainda pendentes de aprovação, o efeito das mesmas para a redução do déficit só se fará sentir no longo prazo. Ou seja, é necessário um certo tempo para que se tenha uma redução substancial da massa de servidores que são regidos pela legislação atual. Estes servidores são protegidos das modificações que ocorrem após seu ingresso no serviço público e, conseqüentemente, é necessário que um número expressivo deles seja extinto, considerando também seus dependentes, para que as novas regras surtam efeito nos resultados das contas previdenciárias.

A metodologia utilizada nesta análise baseia-se nas técnicas da matemática atuarial, as quais estão bem detalhadas em Iyer (1999) e Thullen (1995). O primeiro passo foi dividir a população em análise em quatro subgrupos: os ativos (A), os aposentados por invalidez (I), os aposentados por idade e tempo de contribuição $(\mathrm{P})$ e os pensionistas $(\mathrm{S})$. Essa divisão foi feita com o intuito de manter as características específicas de cada grupo.

Neste estudo considera-se que não haverá mais entrada de servidores no Regime Jurídico Único (RJU), apesar das reformas administrativa e previdenciária efetuadas até o presente não terem ainda excluído por completo a entrada de novos participantes nesse regime. Portanto, a análise é realizada considerando uma massa fechada, não havendo, portanto, fluxo de entrada de ativos.

Porém, apesar do grupo como um todo ser fechado, todos os subgrupos, com exceção dos ativos, são abertos. Ou seja, o único subgrupo que não admite nenhuma causa de entrada é o dos ativos.

Considerando agora as causas de eliminação, mais uma vez o subgrupo dos ativos é peculiar, dado que nos demais subgrupos a única causa de eliminação é a morte. Nos ativos, além da morte, as entradas em invalidez e nas demais aposentadorias também constituem causas de eliminação. Por sua vez, esses são fatores de entrada nos demais subgrupos. Portanto, as causas de eliminação dos ativos são as responsáveis pelas entradas nos demais subgrupos e, conseqüentemente, os torna abertos. 
Depois de feita a projeção do quantitativo dos subgrupos, foi realizada a projeção dos gastos com os mesmos, baseando-se em coortes determinadas pela idade. Com o resultado das projeções do quantitativo e dos gastos foi possível realizar a análise da evolução do déficit. Porém, para que fosse possível calcular o déficit, ainda foi necessário adotar certas hipóteses quanto à contribuição dos servidores. Por fim, foram adotadas algumas hipóteses biométricas e outras econômicas, apresentadas a seguir.

(i) Hipóteses Biométricas:

Tábua de Mortalidade: AT 49

Tábua de entrada em invalidez: ÁLVARO VINDAS

Tábua de mortalidade de inválidos: IAPB 57

Em relação às hipóteses biométricas acima adotadas, cabe observar que, segundo Heligan e Pollard (1993), a partir dos primeiros estudos de Graunt (1662) e Halley (1693), a construção das tábuas de vida foram sucessivamente aprimoradas. Essas estatísticas iniciais consistiam da observação de sobrevida, de um ano para outro, de um grupo de um determinado grupo de pessoas. Somente com Milne (1815) a primeira tábua de vida que utiliza conceitos atuariais é encontrada na literatura demográfica.

A escolha, tanto da taxa de desconto quanto da tábua de mortalidade, é elemento-chave em estudos atuariais. Cabe observar que o nível e a estrutura de mortalidade são variáveis no tempo e de população para população. Porém, não existe consenso sobre qual a tábua mais apropriada a ser utilizada.

A Portaria MPAS $\mathrm{N}^{\circ} 4992$, de 5 de fevereiro de 1999, atualizada pela de $\mathrm{N}^{\mathrm{O}}$ 7796 , de 28 de agosto de 2002, estabelece em seu Art. $2^{\circ}$ que os regimes próprios de previdência social dos servidos públicos devem ser organizados com base em normas gerais de contabilidade e de atuária. Essas últimas normas, que constam no Anexo I da referida portaria, item X - 4, explicita que as tábuas biométricas utilizadas para as avaliaçôes atuariais deverão observar (i) a Tábua de Sobrevivência AT-49 (Male) como limite máximo de taxa de 
mortalidade; (ii) a Tábua de Mortalidade AT-49 (Male) como limite mínimo de taxa de mortalidade; (iii) Entrada em Invalidez - Álvaro Vindas, como limite mínimo de taxa de entrada em invalidez; e (iv) Mortalidade de Inválidos - experiência IAPC, como limite máximo de taxa de mortalidade de inválidos, ou alternativamente outras estatísticas reconhecidas pelas Normas de Atuária do País, como é o caso do IAPB 57 adotado no presente estudo.

A Tábua AT-49 foi desenvolvida por Lumsdem (1949), do Mortality Committy (EUA), observando a taxa de sobrevivência e mortalidade, no período de 1941 a 1946, do grupo de referência, projetando a tábua para cobrir as respectivas probabilidades de 0 a 109 anos. Já a estatística biométrica referente à entrada em invalidez Álvaro Vindas consiste dos resultados de um estudo elaborado pelo mesmo em 1957 para o Departamento Actuarial y Estadístico de la Caja Costarricense de Seguro Social (CCSS). Finalmente, a tábua de mortalidade de inválidos IAPB 57 consiste de resultados obtidos pelo Retirement and Pension for Bank Workers Institute (1934) e o IAPC pelo Retirement and Pension for Commerce Workers Institute (1934).

Neste estudo adotamos como hipótese de trabalho, que não será testada, que as hipóteses biométricas adotadas pela legislação brasileira constituem boa aproximação da evolução futura efetiva das quantidades. ${ }^{10}$

(ii) Hipóteses Econômicas:

Demais causas de eliminação: $0,0 \%$

Crescimento do PIB real: $3,0 \%$

Por outro lado, para analisar as dinâmicas das quantidades e dos gastos, consideraram-se as categorias de ativos, aposentados e pensionistas, na sua classificação de inválidos, pensionistas e aposentados, por gênero e por coorte de idade do ano 1999 como correspondente ao período inicial das simulações. Esses dados primários foram obtidos dos dados primários do Boletim

10 Uma elaboração detalhada de Tábuas de Vida para o Brasil elaboradas a partir de dados da Susep pode ser encontrada em BELTRÃO \& PINHEIRO (2002). 
Estatístico de Pessoal da Secretaria de Recursos Humanos do Ministério do Planejamento. ${ }^{11}$ Cabe ainda observar que as despesas foram obtidas como o produto entre o salário médio e a quantidade de servidores em cada coorte de idade. ${ }^{12}$

Para o entendimento do modelo adotado, são apresentadas as equações que geraram as projeções do quantitativo dos participantes do RJU e, posteriormente, a receita e despesa gerada por esses servidores. Portanto, as equaçóes estão separadas em dois grandes grupos. O primeiro tenta capturar a dinâmica das quantidades, e o segundo a dinâmica dos valores utilizando os resultados do primeiro conjunto de equações.

\subsection{Dinâmica das Quantidades}

Com relação ao primeiro grupo de equações, que permitem o cálculo da evolução do quantitativo da população analisada, elas estão divididas em subgrupos para refletir o fato de que a população divide-se em subgrupos, de acordo com as características de cada um deles: ativos, aposentados por invalidez, aposentados regulares e pensionistas. Em todos os subgrupos são utilizadas tábuas que fornecem as probabilidades de morrer, de se aposentar, de se tornar inválido, e a partir dessas probabilidades são montadas as planilhas que fornecem a dinâmica das quantidades de todos os subgrupos. Ainda dentro de cada subgrupo, a diferenciação por sexo dos participantes é contemplada mediante a inclusão da variável $\mathfrak{g}$, que assumirá o valor 1 quando se considera apenas o sexo masculino, 2 o feminino, e 3 ambos os sexos de forma conjunta.

11 Em 1999 a média das quantidades de ativos chega a 504.081 e o de aposentados e pensionistas a 583.479 , dos quais 30.679 correspondem à categoria de inválidos, 189.601 de pensionistas e 363.199 de aposentados.

12 As despesas com ativos em 1999 corresponde a R\$ 11.598.272.196 e com inativos e pensionistas de R\$ 12.759.041.797. 
(a) Evolução da Quantidade de Ativos

Dentre os diferentes subgrupos, o correspondente aos ativos é o que possui o maior número de variáveis incluídas, dado que constitui o subgrupo que fornece causa de entrada para todos os outros subgrupos. Os ativos são os únicos que podem sofrer todas as causas de eliminação consideradas no modelo, quais sejam: morte, invalidez, aposentadoria por idade ou tempo de contribuição, e outras causas de eliminação.

A equação (1), abaixo, é utilizada para calcular a quantidade de ativos de gênero $g$ no ano $t+1, A_{(\mathscr{g}, t+1)}$. No entanto, ela também pode ser expressa como em (1a), onde, de forma mais clara, reflete que a variação do estoque de ativos de gênero $g$ é igual ao fluxo de entrada menos o fluxo de saída, ou seja, o fluxo líquido de ativos de gênero $g$ no ano $t+1, F E_{(g, t+1)}-F S_{(g, t+1)}$.

$$
\begin{aligned}
& A_{(g, t+1)}=A_{(g, t)}-F S_{(g, t+1)}+F E_{(g, t+1)} \\
& A_{(g, t+1)}-A_{(g, t)}=F E_{(g, t+1)}-F S_{(g, t+1)}
\end{aligned}
$$

Porém, para se ter uma formulação mais precisa da quantidade de ativos, é necessário introduzir a distribuição desses indivíduos por coortes de idade. Para se obter a quantidade de ativos na idade $x$ e gênero $g$ no ano $t, A_{(x, \mathscr{g}, t)}$, a equação (2), abaixo, multiplica a quantidade de ativos existentes no ano anterior, $t$ - 1 , pela probabilidade do ativo não ter morrido, não ter se tornado inválido e não ter se aposentado. Ou seja, são excluídos todos os indivíduos que eram ativos em $\boldsymbol{t}$ - $\mathbf{l}$ e, devido à ocorrência de morte ou de aposentadoria nesse intervalo de tempo, não podem mais continuar em atividade no ano $t$.

Portanto, a probabilidade do indivíduo continuar em atividade no ano $t$ foi calculada retirando todas as probabilidades de ele sofrer alguma das causas de eliminação, sendo elas: a probabilidade de morte de um não-inválido na idade $x-1, q_{(x-1)}$, a probabilidade de entrada em invalidez na idade $x-1, i_{(x}$ -1), a probabilidade de entrada em aposentadoria por idade ou tempo de contribuição na idade $x-1$ e gênero $g, \boldsymbol{o}_{(x-1, \mathfrak{g})}$, e a probabilidade de outras causas de eliminação na idade $x-1, r_{(x-1)}$. Dessa forma, obtêm-se os ativos 
remanescentes de idade $x$ e gênero $g$ no ano $t$ e, adicionando o fluxo de entrada de novos ativos com a mesma idade, gênero e ano considerado, $F E_{(x, \mathfrak{g}, t),} \mathrm{O}$ montante total de ativos do ano $t$.

$$
A_{(x, \mathfrak{g}, t)}=A_{(x-1, \mathfrak{g}, t-1)}\left(1-q_{(x-1)-} i_{(x-1)-} o_{(x-1, \mathfrak{g})-} r_{(x-1)}\right)+F E_{(x, \mathfrak{g}, t)}
$$

Para o cômputo do fluxo de saída de ativos na idade $x$ e gênero $g$ no ano $t$, $F S_{(x, g, t)}$, são consideradas novamente todas as causas de eliminação. Porém, o objetivo da equação (3) é exatamente o oposto da equação (2). Ou seja, na equação (2) o objetivo é calcular os ativos remanescentes, enquanto que na (3) o objetivo é obter todos os ativos que são eliminados. Para isso, multiplica-se a quantidade de ativos pela soma de todas as probabilidades que $\mathrm{o}$ tornam incapaz de continuar em atividade, $q_{x-1}$ : probabilidade de morte de um não-inválido na idade $x-1 ; i_{x-1}$ : probabilidade de entrada em invalidez na idade $x-1 ; \boldsymbol{o}_{(x-1, \mathfrak{g})}$ : probabilidade de entrada em aposentadoria por idade ou tempo de contribuição na idade $x-1$ e gênero $g$, e $r_{x-1}$ : probabilidade de outras causas de eliminação na idade $x-1$.

$$
F S_{(x, \mathfrak{y}, t)}=A_{(x-1, \mathfrak{Y}, t-1)}\left(q_{(x-1)}+i_{(x-1)}+o_{(x-1, \mathfrak{Y})}+r_{(x-1)}\right)
$$

Por sua vez, a equação (4) é uma variação da equação (3), obtida mediante uma manipulação para calcular o fluxo de entrada de ativos de gênero $g$ no ano $t,\left(F E_{(\mathscr{g}, t)}\right)$. Nessa equação tem-se que o fluxo $\boldsymbol{F} \boldsymbol{E}_{(g, t)}$ é igual à soma da variação do estoque de ativos, $A_{(g, t)}-A_{(g, t-1)}$, e do fluxo de saída de ativos de gênero $g$ no ano $t, F S_{(g, t)}$.

$$
F E_{(g, t)}=A_{(g, t)}-A_{(g, t-1)}+F S_{(g, t)}
$$

Para se obter a distribuição do fluxo de entrada de ativos nas diferentes idades foram calculadas, a partir dos dados dos servidores do Executivo Civil que ingressaram no último concurso, as proporções de ingressos nas diferentes coortes de idade. Conhecendo essas proporções, para se obter o fluxo de entrada de ativos na idade $x$ e gênero $g$ no ano $t, F E_{(x, y, t)}$, basta multiplicar o fluxo de entrada de ativos de gênero $g$ no ano $t, F E_{(g, t)}$, pela proporção de ingressos na idade $x$ e gênero $g$ no ano $\left.t, f_{(x, g}, t\right)$. Calculando a 
equação (5), abaixo, para todas as coortes, obtém-se a dinâmica da quantidade de servidores públicos em atividade.

$$
F E_{(x, \mathfrak{g}, t)}=f_{(x, \mathfrak{g}, t)} F E_{(\mathfrak{g}, t)}
$$

Vale ressaltar que a metodologia apresentada nesta seção poderia ser utilizada para análise tanto de massa fechada como de massa aberta, dado que a diferença entre elas consiste apenas no valor utilizado como fluxo de entrada de novos ativos. Porém, não é objeto desse trabalho a análise com massa aberta, sendo toda a análise, aqui realizada, baseada nos cálculos com massa fechada, supondo, portanto, que o fluxo de entrada de ativos é sempre igual a zero.

(b) Evolução da Quantidade de Aposentadorias por Invalidez

A análise da dinâmica da quantidade desse subgrupo é simplificada pelo fato de que somente há uma causa de entrada e uma de saída. Para se obter a quantidade de novos aposentados por invalidez é utilizada a tábua de entrada em invalidez Álvaro Vindas, enquanto que para se calcular a saída utilizase a tábua de mortalidade de inválidos IAPB 57.

A entrada em invalidez na idade $x$ e gênero $g$ no ano $t, N I_{(x, \mathfrak{g}, t)}$, representada pela expressão (6) abaixo, é obtida pela multiplicação dos ativos no ano anterior $t-1$, e conseqüentemente em idade também anterior em um período, e a probabilidade de um indivíduo nesse idade se tornar inválido, $\boldsymbol{i}_{(x-1)}$.

$$
N I_{(x, \mathfrak{g}, t)}=A_{(x-1, \mathfrak{g}, t-1)} i_{(x-1)}
$$

Para se obter o estoque de aposentados por invalidez, como na equação (9) abaixo, é necessário calcular os aposentados que não foram eliminados e adicionar as novas entradas calculadas na equação (6) acima. A quantidade de inválidos remanescentes é obtida pela multiplicação da quantidade de inválidos do ano anterior, $I_{(x-1, g, t-1)}$, e a probabilidade desse inválido não morrer, 1 - $q_{(x-1)}^{i}$, ou seja, um menos a probabilidade dele morrer, como descrita na expressão abaixo. 


$$
I_{(x, \mathfrak{g}, t)}=I_{(x-1, \mathfrak{g}, t-1)}\left(1-q_{(x-1)}^{i}\right)+N I_{(x, \mathfrak{g}, t)}
$$

(c) Evolução da Quantidade de Aposentados

A seguir serão descritas as equações que fornecem a entrada no subgrupo do aposentados e, posteriormente, o total de participantes desse subgrupo, excluindo-se os aposentados por invalidez.

No cálculo de entrada em aposentadoria na idade $x$ e gênero $g$ no ano $t, P_{(x, y, t)}$, conforme a expressão (8) abaixo, multiplica-se a quantidade de ativos na idade $x-1$ e gênero $g$ no ano $t-1, A_{(x-1, g, t-1)}$ pela probabilidade dele se aposentar com idade $x-1, \boldsymbol{o}_{(x-1, g)}$ ou a probabilidade de entrada em aposentadoria por idade ou tempo de contribuição na idade $x-1$ e gênero $g$.

$$
N P_{(x, \mathscr{g}, t)}=A_{(x-1, \mathfrak{g}, t-1)} o_{(x-1, \mathfrak{g})}
$$

Uma vez calculado o número de novos aposentados no ano $t, N P_{(x, \mathfrak{g}, t)}$, e somando a este número a multiplicação da quantidade total de aposentados na idade $\boldsymbol{x}$ - $\boldsymbol{l}$ e gênero $\mathfrak{g}$ no ano $\boldsymbol{t} \boldsymbol{- 1}$ pela probabilidade destes não morrerem, obtém-se a quantidade total de aposentados na idade $x$ e gênero $g$ no ano $t$, $P_{(x, \mathfrak{g}, t)}$, como apresentada na expressão $(9)$, a seguir.

$$
P_{(x, \mathfrak{g}, t)}=P_{(x-1, \mathfrak{g}, t-1)}\left(1-q_{(x-1)}\right)+N P_{(x, \mathfrak{g}, t)}
$$

(d) Evolução da Quantidade de Pensionistas

O último subgrupo a ser considerado é composto pelos pensionistas, no qual encontram-se os representantes dos componentes de todos os outros subgrupos. Diferentemente dos outros subgrupos, este é formado pelos pensionistas que não morreram no ano anterior, $S_{(x-1, t-1)}\left(1-q_{(x-1)}\right)$, e pelos dependentes dos participantes do RJU que faleceram e deixaram a pensão para esses dependentes. Ou seja, nesse subgrupo o que interessa é a soma de: (i) dos contribuintes não-inválidos que se tornam instituidores de pensão, dados pelo produto da quantidade de ativos na idade $x+k$ e ano $t$ e a probabilidade de morte de um não-inválido na idade $x-1, A_{(x+k, t)} q_{(x-1)}$; (ii) do montante dado pela quantidade total de aposentados por invalidez 
na idade $x+k$ e ano $t$ multiplicado pela probabilidade de morte de um nãoinválido na idade $x+k, I_{(x+k, t)} q_{(x+k)}^{i}$; e (iii) o montante da quantidade total de aposentados na idade $x+k$ e ano $t$ multiplicado pela probabilidade de morte de um não-inválido na idade $\boldsymbol{x}+\boldsymbol{k}, \boldsymbol{P}_{(x+k, t)} \boldsymbol{q}_{(x+k)}$. A correspondente somatória é dada pela expressão (10) abaixo. Cabe observar, ainda, a introdução da variável $k$, que constitui uma particularidade desse subgrupo, e que indica a diferença de idade entre o instituidor da pensão e o pensionista. Como não há informação disponível sobre o perfil da família dos contribuintes, adotou-se a hipótese de que os pensionistas são cinco anos mais novos que os instituidores de pensão. Por isso, neste modelo, assume-se que a variável $k$ possui valor 5 .

$S_{(x, t)}=S_{(x-1, t-1)}\left(I-q_{(x-1)}\right)+A_{(x+k, t)} q_{(x+k)}+I_{(x+k, t)} q_{(x+k)}^{i}+P_{(x+k, t)} q_{(x+k)}$

\subsection{Dinámica dos Gastos}

A análise da dinâmica do valor é feita de forma semelhante à realizada para a evolução do quantitativo da massa de servidores. Porém, neste item, o foco principal das equações é o gasto monetário com cada subgrupo. Com isso, para obter o valor despendido com cada um deles, é essencial o uso dos resultados obtidos na dinâmica das quantidades acima.

(a) Evolução dos Gastos com Ativos

$$
W_{(x, g, t)}=W_{\left(x, g, t_{0}\right)} * \prod_{j=t_{0}}^{t}\left(1+\lambda_{j}\right)
$$

A primeira equação da evolução dos gastos com ativos busca capturar a evolução do salário médio, considerando uma determinada faixa de idade. $\mathrm{Ou}$ seja, a idéia da equação (11) é que o salário médio da coorte, determinada pela idade $x$ e gênero $g$ no ano $t, W_{(x, \mathfrak{g}, t)}$, é igual ao salário inicial da análise, $\boldsymbol{t}_{0}$, da mesma coorte, multiplicado pelo produto de todos os reajustes salariais reais, em porcentagem, concedidos ao pessoal ativo, considerando o intervalo de $\boldsymbol{t}_{0}$ até $\boldsymbol{t}$. Por sua vez, a variável $\lambda_{j}$ representa o reajuste salarial real, em porcentagem, concedido ao pessoal ativo no ano $j$. 
Portanto, a evolução do salário médio de todas as coortes é essencial para o cálculo da evolução do gasto com os ativos. Sendo conhecido o valor do salário médio da coorte determinada pela idade $x$ e gênero $g$ no ano $t, W_{(x, \mathfrak{g}, t)}$, basta multiplicá-lo pelo número de ativos na mesma idade, gênero e ano, $A_{(x, y, t)}$, obtendo-se o total de pagamento dos ativos na idade $x$ e gênero $g$ no ano $t, W B_{(x, y, t)}$, como expresso em (12), a seguir.

$$
W B_{(x, \mathfrak{g}, t)}=A_{(x, \mathfrak{g}, t)} W_{(x, \mathfrak{V}, t)}
$$

(b) Evolução dos Gastos com Aposentados por Invalidez

Por sua vez, os aposentados por invalidez têm o direito de receber os mesmos vencimentos que recebiam quando estavam em atividade. Assim sendo, para o cálculo do gasto com os inválidos a variável de despesa continua sendo o salário médio pago aos ativos.

Portanto, a despesa com o fluxo de entrada em invalidez na idade $\boldsymbol{x}$ e gênero $g$ no ano $t, D N I_{(x, y, t)}$, é obtida com o multiplicação do salário médio da mesma coorte, considerando o mesmo ano, pela entrada em invalidez na idade $x$ e gênero $g$ no ano $t, N I_{(x, y, t)}$, obtida na dinâmica da respectiva quantidade (6) acima. Assim, esta categoria de despesa fica expressa como em (13) abaixo.

$$
D N I_{(x, \mathfrak{g}, t)}=N I_{\left(x_{\mathfrak{L}} \mathfrak{g}, t\right)} W_{(x, \mathfrak{g}, t)}
$$

Por outro lado, a despesa com o estoque de aposentados por invalidez, na idade $x$ e gênero $g$ no ano $t, D I_{(x, y, t)}$, expresso em (14) abaixo, é a soma do resultado obtido na equação (13) e os inválidos que não morreram, representados por $\boldsymbol{D} \boldsymbol{I}_{(x, \mathfrak{g}, t)} \boldsymbol{I}-\boldsymbol{q}_{(x-1)}^{i}$ : despesa com inválidos na idade $\boldsymbol{x}$ e gênero $\mathfrak{g}$ no ano $t$ multiplicado pela probabilidade do inválido não morrer na idade $x$-1. Além disso, para calcular o valor correto gasto com os inválidos que não morreram é necessário reajustar seus salários no mesmo montante do reajuste concedido a todos os inativos, ${ }^{13} \boldsymbol{\theta}_{t}$.

13 Até a realização desse trabalho, a regra de reajuste dos inativos é a mesma dos ativos. Este também é um ponto que o governo quer modificar, desvinculando o reajuste dos ativos e dos inativos. Neste trabalho ainda se considera a vinculação do reajuste. 


$$
D I_{(x, g, t)}=D I_{(x-1, g, t-1)} *\left(1-q_{(x-1)}^{i}\right) *\left(1+\theta_{\mathrm{t}}\right)+D N I_{(x, g, t)}
$$

(c) Evolução dos Gastos com Aposentadorias

Este item objetiva quantificar o gasto com os demais aposentados, ou seja, a despesa com o fluxo e com o estoque de aposentados.

O raciocínio para o cálculo da despesa com o fluxo de aposentadorias na idade $x$ e gênero $g$ no ano $t, \operatorname{DNP}_{(x, \mathfrak{g}, t)}$, é idêntico ao da equação (13) acima, mudando apenas a variável de entrada em aposentadoria, neste caso representada pela variável $N P$, como consta da equação (15), abaixo.

$$
D N P_{(x, \mathfrak{g}, t)}=N P_{(x, \mathfrak{g}, t)} W_{(x, \mathscr{g}, t)}
$$

Por sua vez, a despesa com o estoque de aposentados, expresso em (18), abaixo, segue o mesmo raciocínio da equação (14), sendo a análise focada no subgrupo de pessoas que atingiram a idade exigida ou o tempo de contribuição para se aposentarem, e não porque se tornaram inválidos. Com isso, para se obter a probabilidade desse aposentado não morrer, deve-se substituir a probabilidade de morte de um inválido, $q_{(x-1)}^{i}$, usada na equação (14), pela probabilidade de morte de um não-inválido, $\boldsymbol{q}_{(x-1)}$. Além disso, ao invés de somar o resultado obtido na equação (13), soma-se o resultado obtido na equação (15), observando que o reajuste dado é o mesmo para todos os inativos, não importando o tipo de aposentadoria.

$$
D P_{(x, g, t)}=D P_{(x-1, g, t-1)} *\left(1-q_{(x-1)}\right) *\left(1+\theta_{\mathrm{t}}\right)+D N P_{(x, g, t)}
$$

(d) Evolução dos Gastos com Pensionistas

Finalmente, o gasto com os pensionistas, expresso em (17), é calculado baseando-se nos pensionistas do ano anterior que não faleceram, com o respectivo reajuste, e em todos os falecidos dos outros subgrupos que irão gerar pensões para os seus dependentes.

$$
\begin{aligned}
& D S_{(x, t)}=D S_{(x-1, t-1)} *\left(1-q_{(x-1)}\right) *\left(1+\theta_{\mathrm{t}}\right)+W B_{(x+k, t)} * q_{(x+k)}+ \\
& D I_{(x+k, t)} * q_{(x+k)}^{i}+D P_{(x+k, t)} * q_{(x+k)}
\end{aligned}
$$


em que $D S_{(x, t)}$ representa a despesa com pensionistas na idade $x$ e ano $t ; q_{(x)}$ -1) a probabilidade de morte de um não-inválido na idade $x-1 ; t_{0}$ o ano inicial da análise; $\theta_{j}$ o reajuste real em porcentual concedido aos inativos no ano $j ; \boldsymbol{W B}_{(x+k, t)}$ o total de pagamento dos ativos na idade $\boldsymbol{x}+\boldsymbol{k}$ e ano $\boldsymbol{t} ; \boldsymbol{k}$ a diferença de idade em anos entre o instituidor da pensão e o pensionista; $D I_{(x+k, t)}$ a despesa com inválidos na idade $x+k$ e ano $t ; q_{(x+k)}^{i}$ a probabilidade de morte do inválido na idade $x+k$; e $D P_{(x+k, t)}$ a despesa com aposentados na idade $x+k$ e ano $t$.

De posse de todas as equações que descrevem a dinâmica tanto da quantidade quanto das despesas acima apresentadas, procede-se à realização das simulações cujos resultados serão apresentados na seção a seguir.

\section{RESULTADO DAS SIMULAÇÕES PARA O RJU}

Os resultados obtidos com as simulações, utilizando as equações acima descritas, partem do pressuposto de que não haverá mais nenhuma entrada no RJU, ou seja, a presente análise diz respeito a uma massa fechada.

Portanto, considerando a população-alvo como massa fechada, a análise é baseada, como pode ser observado no Gráfico 1, abaixo, na evolução da quantidade de ativos e inativos do executivo federal civil até a extinção de ambos os subgrupos ativos e inativos (aposentados e pensionistas). Verificase que a extinção da massa ocorre em 2090, sendo que a partir de 2072 os valores encontrados são insignificantes. ${ }^{14}$

Infere-se, ainda do Gráfico 1, que o número de inativos é sempre maior do que o de ativos. Essa conclusão era previsível, já que no ano inicial da análise o número de inativos supera o número de ativos em mais de $120 \%$, e considerando que não haverá mais entrada de ativos, não há nenhum mecanismo para reverter essa situação inicial.

14 Os valores serão considerados insignificantes na análise da quantidade de ativos e inativos quando forem inferiores a mil. 


\section{GRÁFICO 1 - EVOLUÇÃO DA QUANTIDADE DE ATIVOS E INATI- \\ VOS DO EXECUTIVO CIVIL - MASSA FECHADA, 2000/ 2090}

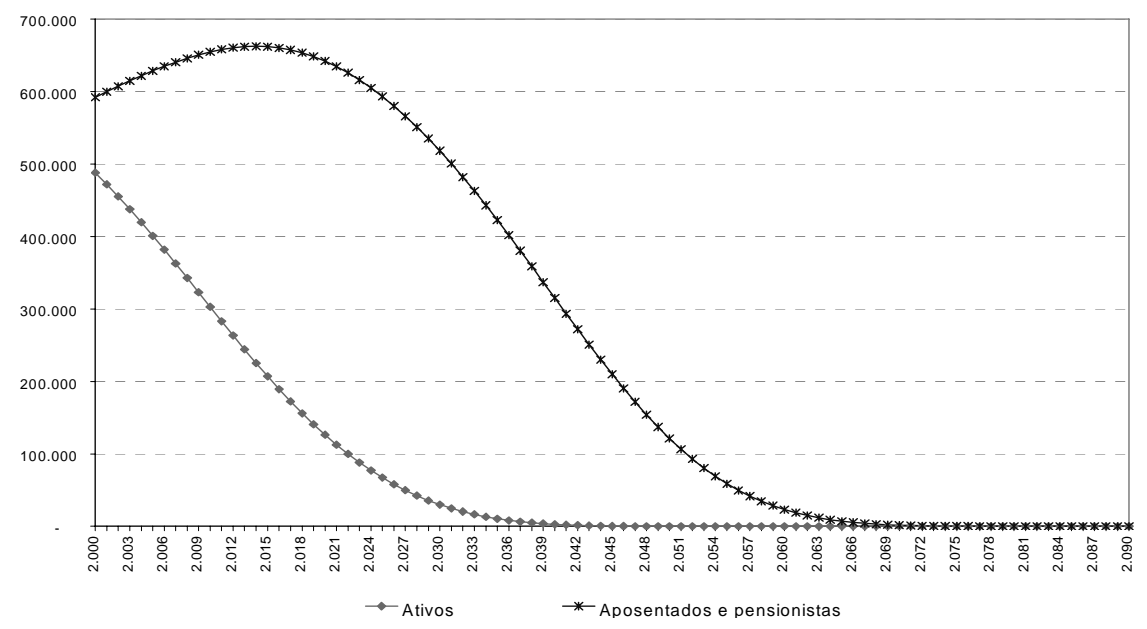

O número máximo de ativos atinge 488.369 participantes no ano inicial, 2000. A partir do ano 2001 esse subgrupo vai diminuindo, sempre a taxas decrescentes, e a partir de 2052 o número de ativos passa a ser nulo. Ou seja, esse ano marca a mudança de toda a população para o subgrupo de aposentados e pensionistas.

Já o número de aposentados e pensionistas começa a análise no ano 2000 com 1.080.405 participantes, e é crescente até 2014. Este é o ano em que os inativos atingem seu máximo de participantes, chegando a um total de 1.662.741. A partir de 2014 o número de inativos começa a decrescer, sendo fácil constatar no Gráfico 4 a respectiva inversão da curva da evolução desses participantes.

Esse comportamento também pode ser explicado por ser uma análise de massa fechada. Nos anos em que há crescimento do número de inativos, pode-se dizer que o número de ativos que estão passando à inatividade está sendo superior ao falecimento dos inativos já existentes. Porém, após quatorze anos, além da quantidade de ativos que passam à inatividade ser me- 
nor, a população inativa também está mais velha e, com isso, com maior probabilidade de morrer. $\mathrm{O}$ ano em que haverá essa inversão dependerá basicamente da idade de entrada no serviço público e da tábua de mortalidade da população geral.

Nos gráficos a seguir é apresentado o comportamento simulado dos déficits do caixa previdenciário dos servidores do Executivo Civil. Primeiramente, para calcular o déficit desses servidores até a extinção da massa fechada, foram considerados quatro cenários diferentes. Esses cenários conjugam hipóteses de contribuições de $11 \%$ e $15 \%$ com base nos ativos e inativos, conforme o quadro a seguir. Vale relembrar que a taxa adotada de crescimento real do PIB é de 3\% para todos os casos.

Cenário 1: contribuição de $11 \%$ dos ativos

Cenário 2: contribuição de $11 \%$ dos ativos e inativos

Cenário 3: contribuição de $15 \%$ dos ativos

Cenário 4: contribuição de $15 \%$ dos ativos e inativos

Nos Gráficos 2 e 3 são apresentados os resultados obtidos nos diferentes cenários de contribuições alternativas consideradas, supondo que os servidores terão reajuste salarial real de $3 \%$, acompanhando o crescimento real do PIB. Observa-se que nos primeiros anos haverá um aumento do déficit em todos os cenários. Esse aumento é explicado pelo aumento do número de inativos, já que os ativos já existentes irão gerar aposentadorias e pensões, e não haverá contrapartida de novos contribuintes devido à inexistência de novas entradas. Como o RJU funciona como um regime de repartição simples, são os ativos do período considerado que pagam os vencimentos dos inativos do mesmo período. Portanto, não há como evitar esse aumento observado do déficit do caixa em todos os cenários.

Vale enfatizar que mesmo havendo contribuição dos inativos, como nos cenários 2 e 4, ainda haveria o aumento do déficit nos primeiros anos. Estimase que os déficits serão máximos, em valores absolutos, no ano de 2029, a saber:

- Cenário 1: R\$ 29,3 bilhões 
- Cenário 2: R\$ 26 bilhões

- Cenário 3: R\$ 29,2 bilhões

- Cenário 4: R \$ 24,8 bilhões

Observando os valores acima, constata-se que a contribuição dos inativos não impede o crescimento do déficit, mas torna-o mais suave. Esta é a medida que tem o maior impacto na contenção do déficit no curto prazo.

\section{GRÁFICO 2 - EVOLUÇÃO DO DÉFICIT DO EXECUTIVO CIVIL EM $R \$$ MILHOES - MASSA FECHADA COM 3\% DE REAJUS- TE SALARIAL REAL, 2000/2090}

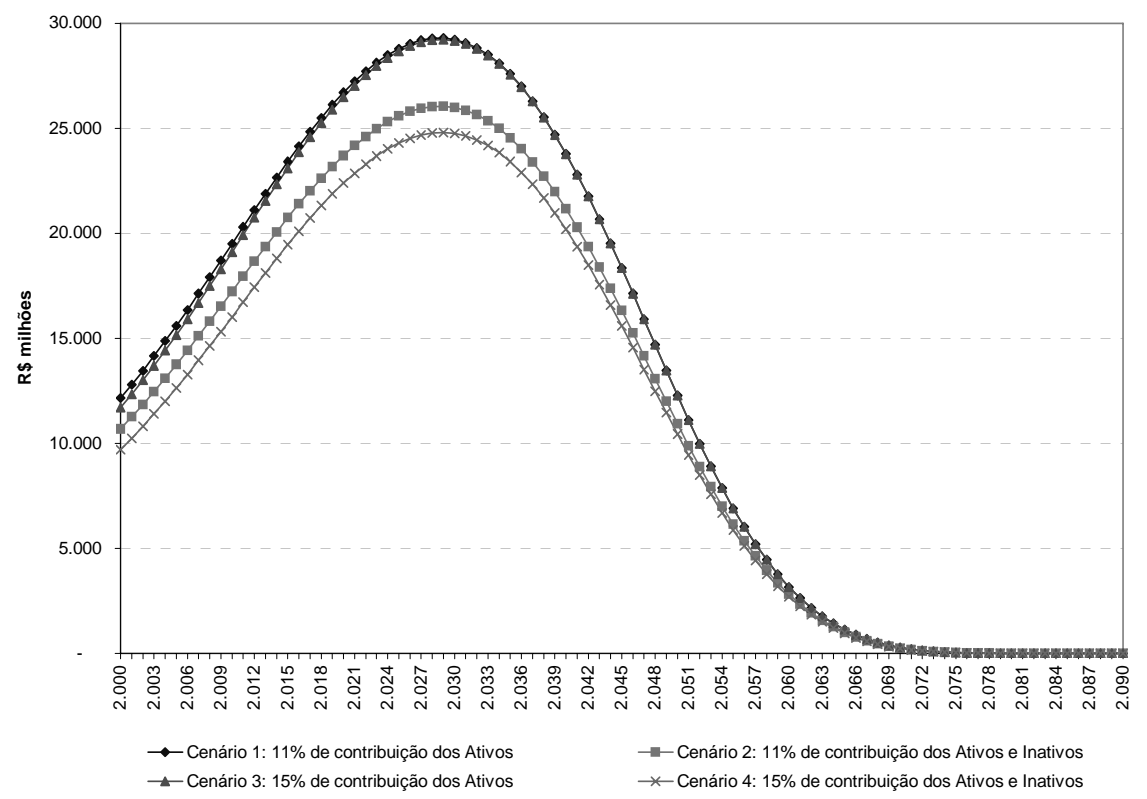

O Gráfico 3 apresenta os mesmos resultados do Gráfico 2, porém com os déficits como porcentual do PIB. Verifica-se que os valores máximos dos déficits como porcentual do PIB são encontrados no ano de 2016. Essa mudança do ano correspondente ao máximo é explicada pela inclusão de mais uma variável estimada, qual seja, o valor do PIB, com o pressuposto de aumento real da mesma de 3\% ao ano. Os gráficos abaixo ilustram que, sob as hipóteses adotadas, o aumento do déficit nos primeiros anos é inevitável. 


\section{G RÁFICO 3 - EVOLUÇÃO DO DÉFICIT DO EXECUTIVO CIVIL COMO \% DO PIB - MASSA FECHADA COM 3\% DE RE- AJUSTE SALARIAL REAL, 2000/2090}

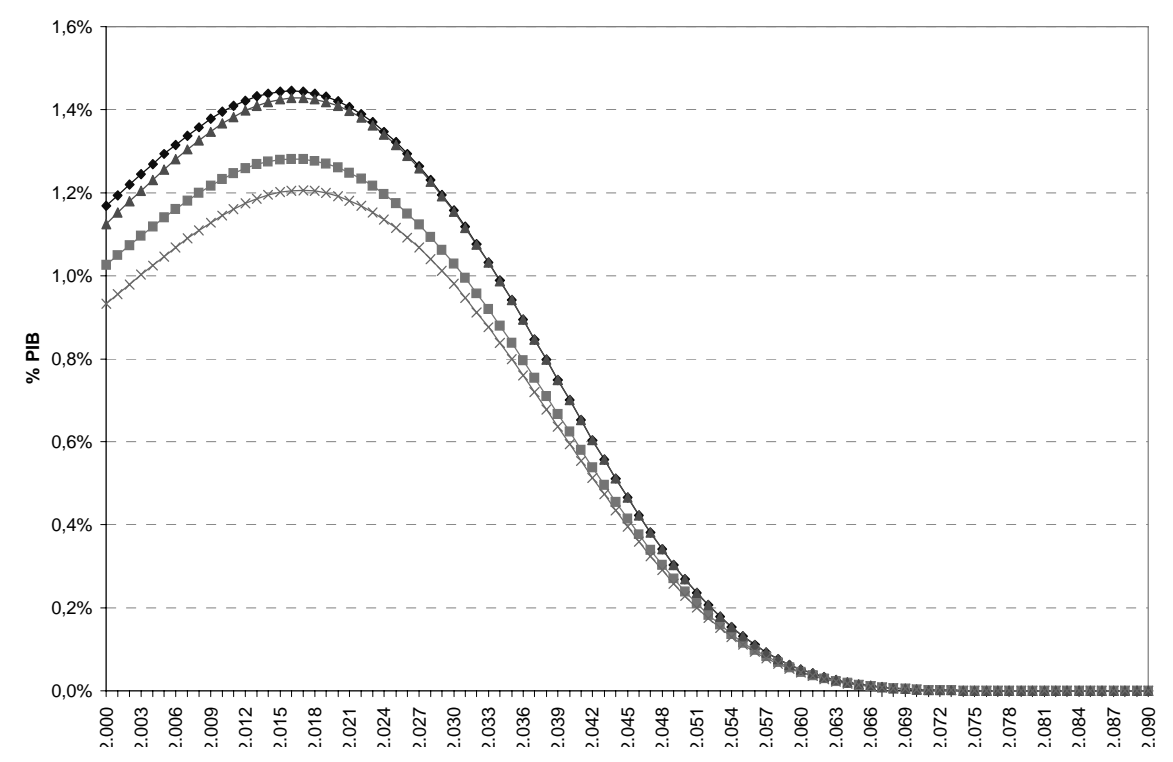

Os cenários do Gráfico 4 são os mesmos da análise anterior, porém o reajuste salarial dos servidores reduziu-se para $1,5 \%$. Com o reajuste menor e mantendo o crescimento do PIB em 3\%, o déficit é menor do que o correspondente ao mesmo cenário da análise anterior, porém o seu aumento, nos primeiros anos, continua inevitável.

Com o reajuste menor, os déficits atingem seu máximo no ano de 2023, mais cedo do que no caso de reajuste salarial de 3\%. Além disso, os valores não são tão elevados, sendo eles:

- Cenário 1: RS 19,8 bilhões

- Cenário 2: RS 17,6 bilhốes

- Cenário 3: R\$ 19,6 bilhões

- Cenário 4: R\$ 16,6 bilhões 
O Gráfico 4 apresenta os déficits como porcentual do PIB, sendo 2009 o ano de máximo atingido. Verifica-se, comparando o Gráfico 3 e 4, que para diminuir o tempo de percepção do resultado das reformas sobre o déficit não é recomendável equiparar o crescimento dos salários ao crescimento do PIB da economia.

\section{GRÁFICO 4 - EVOLUÇÃO DO DÉFICIT DO EXECUTIVO CIVIL COMO \% DO PIB - MASSA FECHADA COM 1,5\% DE REAJUSTE SALARIAL REAL, 2000/2090}

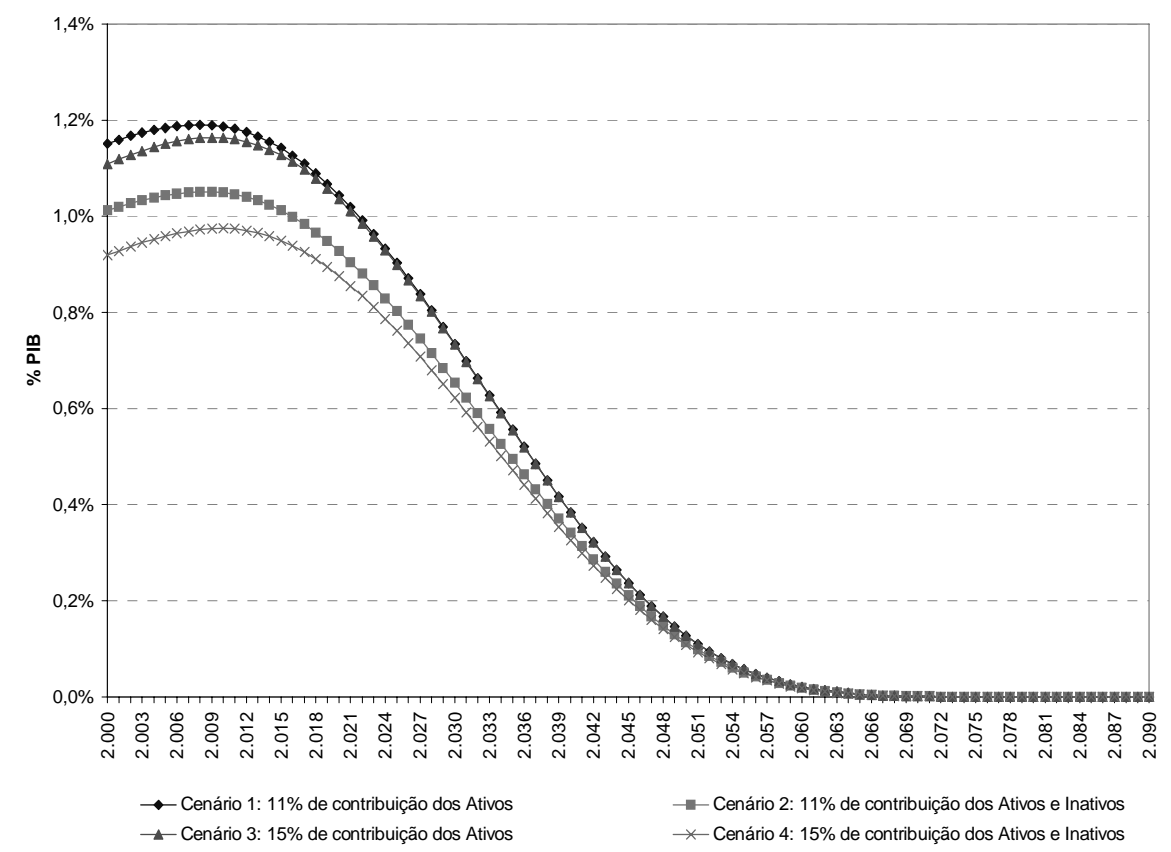

O cenário 4 do Gráfico 4 acima é o mais favorável para as contas públicas, já que a alíquota de contribuição é aumentada para $15 \%$ e incide também sobre os inativos. Além disso, os servidores terão reajuste de $1,5 \%$, enquanto que a economia terá sua taxa de crescimento mantida em 3\%. Mesmo nesse cenário favorável, o déficit máximo atinge 0,975\% do PIB em 2010 e só a partir desse ano é que começará a diminuir.

Mesmo adotando todas as reformas propostas, não há como reduzir o déficit da previdência do setor público no curto e médio prazo. Esse fato pode 
ser explicado pelo tamanho do estoque de inativos. Além disso, até que haja a extinção total do subgrupo de ativos, fato que só ocorrerá em 2051, haverá novas entradas no subgrupo de aposentados.

Analisa-se a seguir o caso extremo onde a economia continua com o crescimento de $3 \%$ ao ano e os servidores não têm reajuste real durante todo o período analisado. Mesmo assim, o déficit em valores absolutos apresentará um aumento nos primeiros anos, atingindo seu máximo no ano de 2016, como pode ser observado no Gráfico 5, abaixo.

\section{GRÁFICO 5 - EVOLUÇÃO DO DÉFICIT DO EXECUTIVO CIVIL EM R\$ MILHÕES - MASSA FECHADA SEM REAJUSTE SA- LARIAL REAL, 2000/2090}

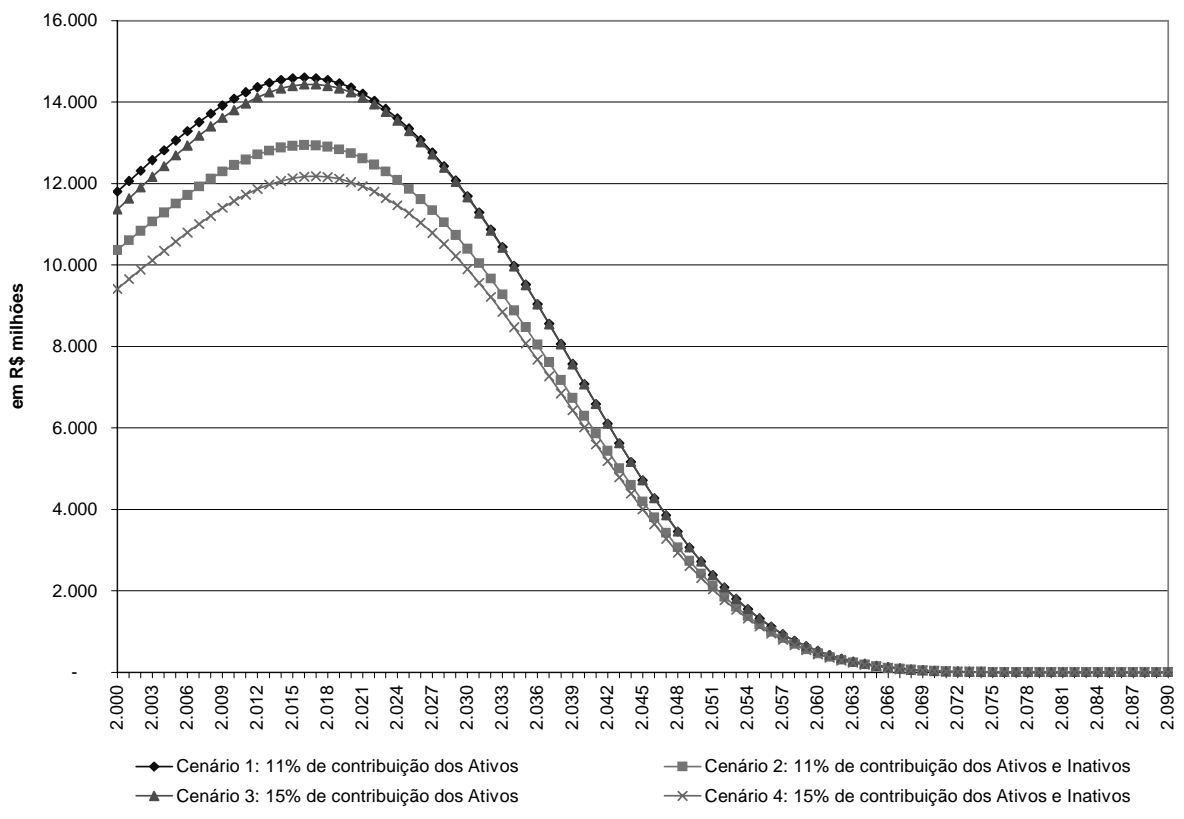


Ou seja, por mais favorável que seja o cenário, supondo que não haverá mais entrada de novos servidores e, conseqüentemente, não haverá novas contribuições, o déficit aumentará em valores absolutos no curto prazo. Os déficits encontrados neste caso são, considerando o ano de máximo: RS 14,6 bilhões (cenário 1); R $\$ 13$ bilhões (cenário 2); R \$ 14,4 bilhões (cenário 3); e R $\$ 12,2$ bilhões (cenário 4).

Por último, os resultados acima são apresentados como porcentual do PIB no Gráfico 6, a seguir. Este constitui o único caso onde haverá uma queda contínua da participação do déficit no PIB, independentemente do cenário analisado, observando que, como conseqüência de todos os parâmetros adotados, também é o caso que apresenta os menores déficits.

\section{GRÁFICO 6 - EVOLUÇÃO DO DÉFICIT DO EXECUTIVO CIVIL COMO \% DO PIBASSA FECHADA SEM REAJUSTE SA- LARIAL REAL, 2000/2090}

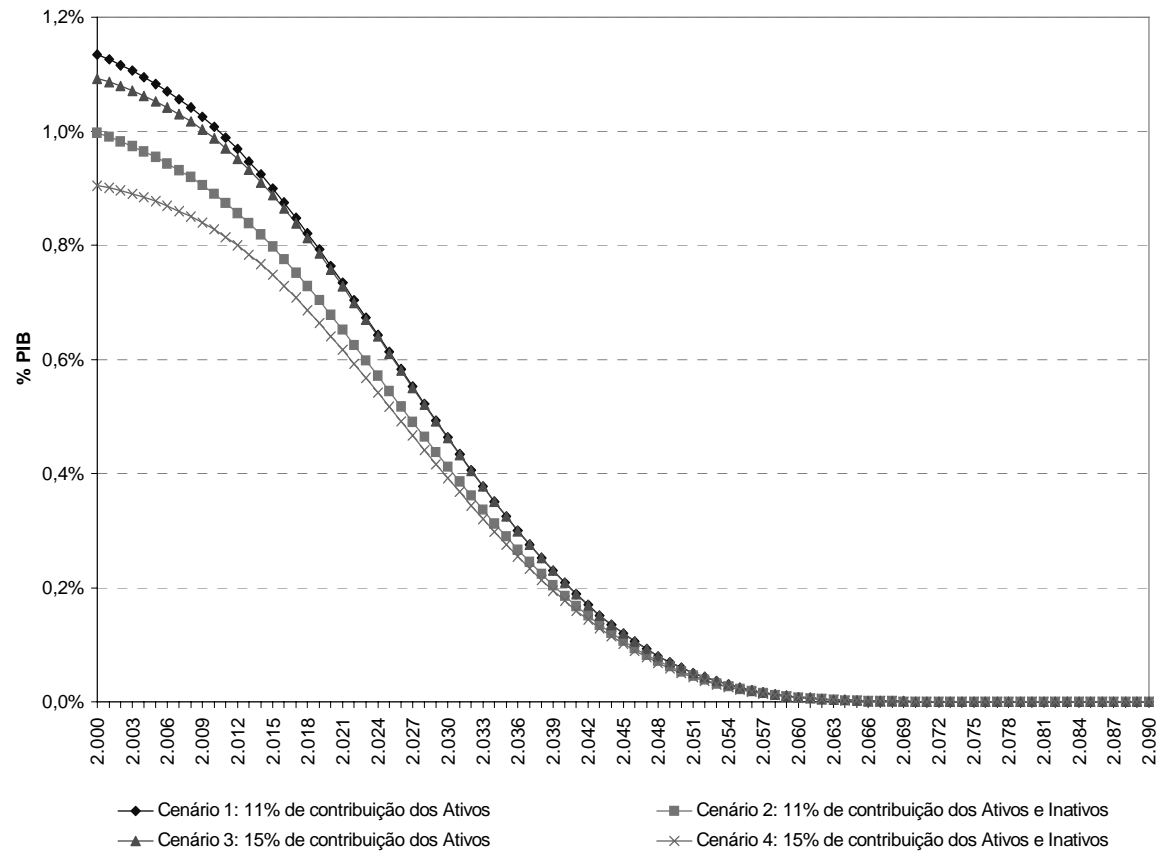


Porém, para que este movimento descendente da curva representativa da relação déficit/PIB seja contínuo, é necessário que a economia tenha um crescimento satisfatório e que os servidores não recebam reajuste real algum, apesar do bom desempenho da economia. Esta é uma suposição forte, porquanto os servidores não receberam reajuste desde a implementação do Real até janeiro de 2002. Além disso, nenhuma categoria organizada aceita ter uma economia tão próspera, com taxa de crescimento real de $3 \%$ ao ano, e continuar recebendo o mesmo salário.

Por fim, na Tabela 1, a seguir, apresenta-se a comparação dos maiores déficits alcançados em todas as simulações efetuadas e, conseqüentemente, o ano que começará o declínio dos déficits.

\section{TABELA 1 - VALORES MÁXIMOS DOS DÉFICITS - CENÁRIOS AL- TERNATIVOS (EM R\$ MILHÕES)}

\begin{tabular}{cccc}
\hline & $\begin{array}{c}\text { Reajuste } \\
\text { salarial de 3\% }\end{array}$ & $\begin{array}{c}\text { Reajuste } \\
\text { salarial de 1,5\% }\end{array}$ & $\begin{array}{c}\text { Sem reajuste } \\
\text { salarial }\end{array}$ \\
\hline Cenário 1: 11\% de contribuição dos Ativos & 29.295 & 19.777 & 14.603 \\
& $(2.029)$ & $(2.023)$ & $(2.016)$ \\
Cenário 2: 11\% de contribuição dos Ativos & 26.049 & 17.567 & 12.943 \\
e Inativos & $(2.029)$ & $(2.023)$ & $(2.016)$ \\
Cenário 3: 15\% de contribuição dos Ativos & 29.218 & 19.662 & 14.429 \\
& $(2.029)$ & $(2.023)$ & $(2.016)$ \\
Cenário 4: 15\% de contribuição dos Ativos & 24.792 & 16.649 & 12.175 \\
e Inativos & $(2.029)$ & $(2.023)$ & $(2.016)$ \\
\hline
\end{tabular}

Na Tabela 1 é fácil visualizar a diferença do montante dos déficits quando há uma diminuição do reajuste salarial dado. Além da variação do déficit, o tamanho do reajuste também altera o ano de pico, sendo eles: 2029 (reajuste de 3\%), 2023 (reajuste de 1,5\%) e 2016 (sem reajuste). Ou seja, quanto menor o reajuste, mais rápido será atingido o máximo e, conseqüientemente, mais cedo começa a diminuição do déficit. 
Ainda podemos observar que, como esperado, em todos os reajustes considerados o máximo déficit atingido será menor no cenário 4 , em que tanto os ativos quanto os inativos contribuem com uma alíquota de $15 \%$. Neste sentido, com um reajuste salarial de $3 \%$, correspondente à taxa hipotética de crescimento do PIB real da economia, esse cenário produz um déficit máximo $15,37 \%$ inferior ao gerado pelo cenário 1 , em que somente os ativos contribuem com 11\%. Já no caso extremo, em que os salários do funcionalismo sob o RJU não são reajustados, o cenário 4 produz um déficit máximo $16,63 \%$ inferior ao cenário 1 . Portanto, quanto maior e mais abrangente a contribuição ao RJU, e menor o reajuste salarial contemplado, mais forte será o impacto sobre o déficit do RJU. Quantitativamente, passando no mesmo cenário 4 de um reajuste salarial de $3 \%$ a um reajuste nulo, gerase uma redução do máximo déficit de mais de $50 \%$ e uma diminuição de 13 anos para começar a observar o declínio do déficit do RJU.

Finalmente, na Tabela 2 são apresentados os valores presentes dos déficits, calculados para todos os cenários e reajustes, assim como as respectivas participaçôes no valor presente do PIB, considerando todos os anos até a extinção da massa em 2090, utilizando uma taxa de desconto de $10 \%$, e supondo uma taxa de crescimento do PIB real de $3 \%$.

TABELA 2 - VALORES PRESENTES DOS DÉFICITS - CENÁRIOS ALTERNATIVOS (EM R\$ BILHÕES)

\begin{tabular}{cccc}
\hline & $\begin{array}{c}\text { Reajuste } \\
\text { salarial de 3\% }\end{array}$ & $\begin{array}{c}\text { Reajuste } \\
\text { salarial de 1,5\% }\end{array}$ & $\begin{array}{c}\text { Sem reajuste } \\
\text { salarial }\end{array}$ \\
\hline Cenário 1: 11\% de contribuição dos Ativos & 200,5 & 167,3 & 141,9 \\
& $(1,17 \%)$ & $(0,98 \%)$ & $(0,83 \%)$ \\
Cenário 2: 11\% de contribuição dos Ativos & 177,2 & 147,8 & 125,4 \\
e Inativos & $(1,04 \%)$ & $(0,87 \%)$ & $(0,74 \%)$ \\
Cenário 3: 15\% de contribuição dos Ativos & 196,5 & 163,7 & 138,7 \\
Cenário 4: 15\% de contribuição dos Ativos & $(1,15 \%)$ & $(0,96 \%)$ & $(0,81 \%)$ \\
e Inativos & 164,7 & 137,1 & 116,1 \\
\hline
\end{tabular}

Último ano da série: 2090.

Taxa de crescimento do PIB real: $3 \%$ anual.

Taxa de desconto: $10 \%$. 
A Tabela 2 demonstra que, com um reajuste salarial de 3\%, similar à taxa anual hipotética de crescimento do PIB real, o déficit do RJU, em termos de valor presente, diminui aproximadamente $17,86 \%$ quando a contribuição aumenta de 11\%, somente dos ativos (cenário 1), para 15\%, imposta tanto sobre ativos quanto inativos. Observa-se também que, neste caso, a participação do valor presente do déficit no valor presente do PIB real cai, ceteris paribus, de $1,17 \%$ para $0,97 \%$. Um impacto ainda maior se obtém caso o funcionalismo sob o RJU não seja contemplado com nenhum reajuste salarial e com uma alíquota de contribuição dos ativos e inativos de $15 \%$. Neste caso, o valor presente do déficit diminui para R \$ 116,1 milhões, que representa, aproximadamente, $0,68 \%$ do valor presente do PIB real simulado da economia.

\section{CONCLUSÃO}

A discussão da reforma previdenciária brasileira não é nova, tampouco é recente o problema do déficit do sistema. Vários motivos levaram à existência desse saldo negativo e crescente, podendo ser destacado a Constituição de 1988. Apesar desta ter sido um avanço no campo dos direitos sociais, não foram considerados os meios para poder viabilizar financeiramente os aumentos resultantes dos gastos do governo.

Embora a Constituição tenha sido promulgada em 1988, as leis que regularizaram as mudanças do regime previdenciário foram sancionadas somente em 1991, retardando, assim, o impacto fiscal que estas vieram a causar.

No caso dos servidores públicos, a Constituição instituiu o RJU, transferindo um grande número de servidores, que antes pertenciam ao RGPS, para o novo regime previdenciário. Essa mudança foi responsável por uma grande transferência de ônus para o governo, estendendo a todos os servidores o recebimento da aposentadoria correspondente ao último salário do servidor.

Por fim, destaca-se a falta de adaptação dos regimes ao novo padrão demográfico encontrado no País. Este foi um problema enfrentado por vários países, principalmente países como o Brasil, que adotaram o sistema de repar- 
tição simples. Esse sistema entra em colapso com o envelhecimento da população, que vem sendo verificado em todo o mundo.

Portanto, era clara a necessidade de reforma de todo o sistema previdenciário brasileiro. Porém, além de ser um problema difícil de se solucionar, existem também interesses políticos que dificultam ainda mais a implementação de uma reforma eficaz. A discussão dessa reforma se iniciou em 1995, e até o presente momento existem pontos pendentes, dependendo de aprovação do Congresso Nacional.

Este trabalho foi realizado com o objetivo de analisar o impacto das reformas, tanto efetuadas quanto propostas, sobre os resultados das contas do RJU. Esse regime foi escolhido pelo tamanho do seu déficit e, conseqüentemente, pelo seu maior impacto financeiro nas contas públicas do governo. O mesmo foi desenvolvido por meio de simulações envolvendo unicamente o sistema previdenciário do executivo federal - RJU, enfocando análises dinâmicas deste regime, considerando que o mesmo não terá novas entradas. Ou seja, supondo que a partir de agora só existirá o RGPS e que o RJU só contará com os participantes que já fazem parte do regime.

Nesta análise coletiva foi aplicado um modelo atuarial no qual os servidores do Executivo Civil foram divididos em quatro subgrupos: os ativos, os aposentados por invalidez, os aposentados por idade e tempo de contribuição, e os pensionistas. Após feita a separação dos grupos, que respeita as características de cada um deles, adotou-se a idéia de que não haverá mais entradas no RJU. A análise passa a ser então do comportamento do grupo já existente e seu respectivo custo para o governo.

De todas as simulações realizadas, a que apresentou o melhor resultado para as contas públicas supõe que o PIB cresce 3\% ao ano, e durante o mesmo período os servidores não terão nenhum reajuste real dos salários. Mesmo com esse cenário favorável e extremo desde o ponto de vista salarial dos funcionários sob o RJU, dado que serão extintas as novas entradas e que, conseqüentemente, também serão extintas novas contribuições, como o sistema é de repartição simples, não há como impedir um crescimento do déficit, em valores absolutos, num primeiro período. Assim, ainda nesse caso, so- 
mente a partir do ano de 2016 é que começará a se observar uma queda do déficit do sistema.

Observa-se também, nas simulações efetuadas, que as reformas, por mais eficazes que sejam, requerem um certo tempo para surtir efeito devido ao fato de que o problema do déficit previdenciário é de estoque, dado pela quantidade muito grande de servidores que já possuem o direito adquirido à aposentadoria seguindo as regras antigas. Portanto, não há como esperar resultados favoráveis no curto e médio prazo. Da mesma forma que existe uma demora para se observar os efeitos das reformas implementadas para equacionar os problemas existentes na estrutura do sistema previdenciário de forma geral, também demandará tempo para se obter os efeitos positivos das reformas propostas para o RJU que poderiam ter um impacto positivo sobre as contas públicas.

\section{BIBLIOGRAFIA}

ALÉM, A. C. D.; GIAMBIAGI, F. Despesa previdenciária: análise de sua composição, efeitos da inflação e bases para uma alternativa intermediária de reforma. Texto para Discussão n. 374. Departamento de Economia da PUC/RJ, setembro, Rio de Janeiro, RJ, 1997.

BARRETO, F. Três ensaios sobre reforma de sistemas previdenciários. 1997. Tese (Doutorado), EPGE/FGV/RJ.

BELTRÃO, K. I.; PINHEIRO, S. S. Estimativa de mortalidade para a população coberta pelos seguros privados. Texto para Discussão $n .868$, IPEA/RJ.

ELLERY, R.; BUGARIN, M. N. S. Previdência social e bem-estar no Brasil. Revista Brasileira de Economia, v. 57, 2003 (forthcoming).

FELDSTEIN, M. (org.). Privatizing social security. EUA: National Bureau of Economic Research and University of Chicago Press, 1998.

GIAMBIAGI, F; ALÉM, A. C. D. A despesa previdenciária no Brasil: evolução, diagnóstico e perspectivas. Texto para Discussão $n .^{\circ}$ 57, Rio de Janeiro, RJ: BNDES, maio 1997.

A crise da Previdência Social. In: GIAMBIAGI, F.; FRANCO, G. (orgs.), Finanças públicas: teoria e prática no Brasil. Rio de Janeiro, RJ: Editora Campus, 1999.

HELIGMAN, L.; POLLARD, J. H. Readings in population research methodology. United Nations Population Fund, v. 2, 1993. 
HEMMING, R. ¿Las pensiones públicas debem ser capitalizadas? Revista de Seguridad Social, Asociación Internacional de la Seguridad Social, Genebra, v. 52, 1999.

IYER, S. Actuarial mathematics of social security pensions. Genebra, Suíça: International Labour Office (ILO) and the International Social Security Association (ISSA), 1999.

LANNES JR., O. P. Aspectos macroeconômicos da reforma da previdência social no Brasil: duas análises em equilíbrio geral com restrições ao crédito. 1999. Tese (Doutorado), EPGE/FGV/RJ.

NAJBERG, S.; IKEDA, M. Previdência no Brasil: desafios e limites. In: GIAMBIAGI, F.; MOREIRA, M. M. (orgs.), A economia brasileira nos anos 90. Rio de Janeiro, RJ: BNDES, 1999.

NIETO, U.; VEGAS, J. Matemática actuarial. Madrid, Espanha: Editorial Mapfre, 1993.

OLIVEIRA, F. E. B.; BELTRÃO, K. I.; FERREIRA, M. G. Reforma da previdência. Texto para Discussão n. 508. Rio de Janeiro, RJ: IPEA, agosto 1997.

OLIVEIRA, F. E. B.; BELTRÃO, K. I.; GUEDES, E. Perspectivas econômico-financeiras da seguridade social após a Nova Constituição. In: Perspectivas da Economia Brasileira 1992, Brasília, DF: IPEA, 1991.

ORNÉLAS, W. O novo modelo previdenciário brasileiro: uma fase de transição. Apresentado no XI Fórum Nacional, Rio de Janeiro, RJ: BNDES, 1999.

ORNÉLAS, W.; VIEIRA, S. P. Novo rumo para a previdência brasileira. Revista BNDES, v. 12, n. 6, p. 31-48, dezembro 1999.

PARK, C. S.; SARP-BETTE, G. Advanced engineering economics. New York, NY: John Wiley \& Sons, INC, 1999.

PINHEIRO, V. C. Reforma da previdência e federalismo: o caso brasileiro. Conjuntura Social do Ministério da Previdência Social, Brasília, DF: Ministério da Previdência e Assistência Social, v. 10, n. 1, p. 7$25,1999$.

PINHEIRO, V. C.; VIEIRA, S. P. A nova regra de cálculo dos benefícios: o fator previdenciário. Informe de Previdência Social, Brasília, DF: Ministério da Previdência e Assistência Social, v. 11, n. 11, p. 1-6, novembro, 1999.

STIGLITZ, J. A. Economics of the public sector. New York, NY: Norton Books, 1988.

TULLEN, P. Técnicas actuariales de la seguridad social - regímenes de las pensiones de invalidez, de vejez y de sobrevivientes. Colecciones In- 
formes OIT, n. 43. Espanha: Ministerio de Trabajo y Seguridad Social, 1995.

VELLOSO, R. A situação das contas públicas após o Real. In: VELLOSO, J. P. R. (coord.), O Brasil e o mundo no limiar do novo século. $2 \mathrm{v}$. Rio de Janeiro, RJ, 1998.

VINDAS, Álvaro. Seguro de invalidez, vejez y muerte. Estúdio Actuarial, San José, Costa Rica: Departamento Actuarial y Estadístico de la Caja Costarricense de Seguro Social, 1957.

Este artigo corresponde a uma versão simplificada da Monografia homônima, terceira colocada no VI Prêmio do Tesouro Nacional (2001), em Tópicos Especiais de Finanças Públicas.

As autoras agradecem a Marcelo Abi-Ramia Caetano pela contribuição na modelagem atuarial, e Osmar Lannes Jr. e Roberto de Góes Ellery Jr. pelos cuidadosos comentários recebidos.

e-mail: paula.magalhaes@fazenda.gov.br

e-mail: mirta@unb.br

(Recebido em março de 2002. Aceito para publicação em julho de 2004). 
ANEXO

TABELA I - PREVIDÊNCIA DO SERVIDOR PÚBLICO - UNIÃO (EM $R \$ B I L H \tilde{O E S})$

\begin{tabular}{lccccc}
\hline & 1995 & 1996 & 1997 & 1998 & $1999^{*}$ \\
\hline Contribuição dos Servidores & 2,1 & 2,58 & 2,58 & 2,63 & 5,4 \\
Despesa com Benefícios & 15,46 & 17,39 & 19,68 & 20,95 & 24,9 \\
Déficit** & $-15,59$ & $-15,87$ & $-17,53$ & $-18,32$ & $-19,5$ \\
Var. \% do Déficit & & 2 & 11 & 5 & 4 \\
\hline
\end{tabular}

* Valores estimados pelo MPAS/SPS, ** 1995 a 1998, a preços de dez/1998; 1999 preços correntes.

TABELA 2 - VALORES MÁXIMOS DOS DÉFICITS - CENÁRIOS ALTERNATIVOS - EM R\$ MILHÕES

\begin{tabular}{cccc}
\hline & $\begin{array}{c}\text { Reajuste } \\
\text { salarial de 3\% }\end{array}$ & $\begin{array}{c}\text { Reajuste } \\
\text { salarial de 1,5\% }\end{array}$ & $\begin{array}{c}\text { Sem reajuste } \\
\text { salarial }\end{array}$ \\
\hline Cenário 1: 11\% de contribuição dos Ativos & 29.295 & 19.777 & 14.603 \\
& $(2.029)$ & $(2.023)$ & $(2.016)$ \\
Cenário 2: 11\% de contribuição dos Ativos & 26.049 & 17.567 & 12.943 \\
e Inativos & $(2.029)$ & $(2.023)$ & $(2.016)$ \\
Cenário 3: 15\% de contribuição dos Ativos & 29.218 & 19.662 & 14.429 \\
Cenário 4: 15\% de contribuição dos Ativos & $(2.029)$ & $(2.023)$ & $(2.016)$ \\
e Inativos & 24.792 & 16.649 & 12.175 \\
\hline
\end{tabular}


TABELA 3 - VALORES PRESENTES DOS DÉFICITS - CENÁRIOS ALTERNATIVOS - EM R\$ BILHÕES

\begin{tabular}{cccc}
\hline & $\begin{array}{c}\text { Reajuste } \\
\text { salarial de } 3 \%\end{array}$ & $\begin{array}{c}\text { Reajuste } \\
\text { salarial de 1,5\% }\end{array}$ & $\begin{array}{c}\text { Sem reajuste sal- } \\
\text { arial }\end{array}$ \\
\hline Cenário 1: 11\% de contribuição dos Ativos & 200,5 & 167,3 & 141,9 \\
& $(1,17 \%)$ & $(0,98 \%)$ & $(0,83 \%)$ \\
Cenário 2: 11\% de contribuição dos Ativos & 177,2 & 147,8 & 125,4 \\
e Inativos & $(1,04 \%)$ & $(0,87 \%)$ & $(0,74 \%)$ \\
Cenário 3: 15\% de contribuição dos Ativos & 196,5 & 163,7 & 138,7 \\
Cenário 4: 15\% de contribuição dos Ativos & $(1,15 \%)$ & $(0,96 \%)$ & $(0,81 \%)$ \\
e Inativos & 164,7 & 137,1 & 116,1 \\
\hline
\end{tabular}

Último ano da série: 2090

Taxa de crescimento do PIB real: $3 \%$ anual

Taxa de desconto: $10 \%$. 